International Journal of Linguistics, Literature and Translation

ISSN: 2617-0299 (Online); ISSN: 2708-0099 (Print)

DOI: 10.32996/ijltt

Journal Homepage: www.al-kindipublisher.com/index.php/ijltt

\title{
Assessing the Listening Proficiency of ESL Students in a Pandemic
}

\author{
Chester B. Esnara 8 iD \\ Assistant Professor, Benguet State University/University of the Cordilleras, Philippines \\ Corresponding Author: Chester B. Esnara, E-mail: c.esnara@bsu.edu.ph
}

\section{ARTICLE INFORMATION \\ Received: March 13, 2021 \\ Accepted: April 10, 2021 \\ Volume: 4 \\ Issue: 4 \\ DOI: $10.32996 / i j l t .2021 .4 .4 .10$}

\section{KEYWORDS}

Assessing, Listening Skills, Grammatical Competence, Inflectional Patterns, ESL Students, Online Learning in a Pandemic

\section{ABSTRACT}

The debate as to whether or not listening skills can be used as a testing device for measuring language proficiency-particularly grammatical competence-has been quite a controversial issue for the longest time. Yet, current research findings have not been entirely conclusive and sufficient either way. Hence, this particular study was conducted to address the problem given the existing research gap in the field. Firstly, the investigation sought to determine the listening proficiency level of $40 \mathrm{ESL}$ freshmen in a state university for grammatical distinctions utilizing the mean score. Secondly, it identified the learners' common errors and difficulties encountered in listening for grammatical distinctions using frequency and sentence analysis. To validate the results of the communicative listening test, a writing composition exercise was duly administered. The results showed that the respondents have very good proficiency levels in listening for grammatical distinctions in terms of inflectional patterns of singular and plural forms of subjects or predicates and good proficiency levels in terms of inflectional patterns for present and past tense of verbs. However, it was found that there still exist some problems in terms of more complex syntactic constructions. Results revealed that the respondents were confused and disrupted in some listening items when the test sentence is embedded with intervening words, phrases, or subordinate clauses. This problem may actually be indicative of sociopsycholinguistic factors to retain what they learned in an academic setting, but outside of it, the intervening words easily disrupted their concentration and memory. Lastly, the new normal caused by the COVID 19 pandemic has forced educators and students into a new learning environment: the online classroom. In recognition of this, the test was administered online, and the results similarly processed but with consideration of the electronic platform as a moderating variable. This shift in the modality of instruction affects ways of learning that have not necessarily been plotted before, as observed by EFL and ESL experts like Brown (2000) and Richards (2016). Thus, while it is not the primary focus of the study, this paper nevertheless highlights this new socio-technological aspect as a crucial moderator of listening assessment for better grammatical competence.

\section{Introduction}

Listening is one of the five fundamental linguistic skills, the other four being speaking, reading, writing, and viewing (Brown 1997, 2000). It is vital in language learning, language acquisition, and overall communicative competence as every essential skill is interrelated and interconnected with the rest in a scaffolding continuum (Richards 1997,2016). However, of the five language skills, listening is the language modality used most frequently given the actual time and dynamic exchange in a highly oral civilization and has expanded into virtual online chats and zoom teleconferences. Because of the fast-changing environment for learning that is recently complexified by the global pandemic, language learning has become an even more significant challenge for all contexts. Dictionary.com (2020) defines "listen" as "to give attention with the ear; attend closely for the purpose of hearing; give ear." In her studies, Schwartz (2001) estimates that language learners spend almost half their communication time listening

\begin{tabular}{ll|ll}
$\mathbf{K}$ & C & AL-KINDI CENTER \\
$\mathbf{R}$ & $\mathbf{D}$ & FOR RESEARCH AN &
\end{tabular} R D DEVELOPMENT Your gateway to world-class research

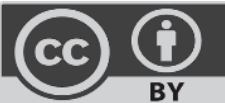

Published by Al-Kindi Center for Research and Development, London, United Kingdom. Copyright (c) the author(s). This open access article is distributed under a Creative Commons Attribution (CC-BY) 4.0 license 
and that students may receive as much as 90 per cent of their in-school information through listening to instructors and to one another. As Schwartz (2001) observes; however, language learners do not recognize the level of effort to develop their listening ability. This general behavior of learners is attributed to the fact that listening is a spontaneous and natural component of daily life (Brown 1997,2000).

Wolfe (2001), as cited by Corpuz, Salandanan, and Rigor (2007), asserts that language learning requires intentional listening that employs strategies for identifying sounds and making meaning from them. This is in line with CLTA principles that revolutionized language teaching and learning since the early 1980s (Celce-Murcia 2003, Brown 1997, Richards 1997, 2016). Wolfe's pedagogical advice is for ESL teachers and students to recognize the power of senses, especially the listening sense, to improve knowledge about language structure, increase retention, and plan instruction accordingly.

Listening, other than writing, has also been widely known as a testing device for measuring language proficiency, particularly in grammar. Brown (2000) underscores that "Listening must be seen as a communication technique that stimulates open and frank exploration of ideas and feelings and enables trainers to establish trust and rapport with participants." As Croom Helm Cross (1998) asserts, quoted in Renukadevi (2014), "without listening skill, no communication can be achieved." In this investigation, the $40 \mathrm{ESL}$ college freshmen were tested to discriminate grammatical units adding to the sum of communicative meaning in discourse.

However, using listening as a language testing technique has encountered huge opposition. Al-Batal (2010) admits that "the listening skill was for a long time relegated to a marginal place in foreign language curricula." One of the most substantial claims made against listening has been offered by Lado (1998). He considers it as having very little value in testing language proficiency, believing that since everything is dictated to the learner, listening cannot measure any language aspect. Lado goes even further and considers it is just a test of spelling and auditory skills. Likewise, Harris (2000), as cited by Zhou (2003), believes that listening sessions are not a teaching device. Zhou (2003) claims that they can merely help learners practice oral/auditory comprehension. Similarly, Vilamin (1998) considers listening as a method of both testing and learning only when learners are proficient in other aspects of language learning.

On the other hand, the proponents of listening as both a learning skill and a testing device advocate that it is a good means for measuring language proficiency. Dictionary.com's (2020) definition is especially indicative: "attend closely for hearing." Its third definition further elucidates the act as a skill: "to wait attentively for a sound" or, for our purposes, to wait attentively for a language. Bonet (2003) and Schwartz (2001) both believe that because listening tests trigger the learner's internalized expectancy grammar, it can give ESL teachers vital information about their overall language proficiency. Canale and Swain (1985) claim that communicative competence is never complete without listening competence; henceforth, listening skills should be given utmost pedagogical importance as a learning skill, and a means to scaffold communication skills.

Research studies show that good listening skills can help learners improve different aspects of their language proficiency. For instance, both Leki (2000) and Miller (1998) conclude that listening as a technique and, more importantly, as a learning activity helps students develop their accuracy in listening and writing and reinforces structure and vocabulary. This view is shared by Brown $(1997,2000)$ that good listening skills ultimately impact overall language proficiency as both micro and macro skills for listening promote general communicative competence. When a learner, for example, can do chunking and microselection while listening to a dialogue, his grammatical accuracy is fostered while developing his discourse competence. In the study of Fabella (2016), she found her ESL high school students getting better grammatical test results when exposed to various listening strategies to cope with different discourses. Experts in ELT have been consistently espousing the explicit teaching of listening strategies to promote higher levels of listening literacy for more effective communication in all types of language learning contexts. Likewise, listening proficiency tests have to be designed along with the tenets and principles of CLTA for any listening program or curriculum to be relevant and responsive to the changing listening needs and abilities of the $21^{\text {st }}$ Century learners, especially with the rise of online learning and its latest advances.

The realization of the importance of listening in overall human communicative activity has led to the conclusion that teaching and assessing listening are essential. Therefore, there seems to be an urgent need for another study to assess learners' listening skills and investigate the common problems they encounter to improve their language proficiency as a formative strategy. This research is an attempt to deal with this issue.

\subsection{Statement of the Problem}

This study sought to determine the level of proficiency and the common error in listening for grammatical distinctions, particularly on inflectional patterns among first-year college students. The test was administered online due to the coronavirus pandemic. Specifically, the Google Meet app was used. Resolving any great technological inequalities (e.g., bandwidth, quality of 
audio from headphones and laptops), several factors in this shifted mode of "new normal" instruction had to be done to mitigate their impact on the results of the investigation. Also, the other intervening variables, such as the lack of a real study room that could affect student concentration, online distractions, noise, etc., were considered. For the writing component and to observe research validity and reliability given the new online modality, student compositions were submitted through Google Forms.

The online test sought answers to the following questions:

1. What is the proficiency level of the 40 college freshmen in listening for grammatical distinction in terms of:

a. inflectional patterns for singular and plural forms of subjects and predicates?

b. Inflectional patterns for present and past tenses of verbs?

2. What are the common errors committed by the subjects of the study in listening for grammatical distinctions in terms of:

a. inflectional patterns for singular and plural forms of subjects and predicates?

b. Inflectional patterns for present and past tense of verbs?

\section{Methodology}

The descriptive-explorative design of the research was used in this study. This was to get a more general picture of the listening proficiency tied up with the target population's grammatical competency. The culled data were treated using the mean score for assessing the proficiency level and frequency for the respondents' common errors in listening for grammatical distinction in terms of inflectional patterns. Interpretive analysis followed guided by the theoretical and conceptual frameworks of the study highlighting Communicative Language Teaching Approach or CLTA as espoused by Brown (1987, 2000); Richards (1997, 2016); Canale and Swain (1985). CLTA principles look at ELT or English Language Teaching as holistic and communicative with the five language skills interconnected and scaffolding one another in the learning continuum. The development of one overlaps with the others, and this integrative language learning is expedited by communicative approaches to listening, speaking, reading, writing, and viewing.

Moreover, communicative instructional materials like communicative grammar tests that consider learners' present ability, difficulties, needs, and sociocultural backgrounds promote holistic second language acquisition. Stephen Krashen's (1985), as cited in Lorenzo Orillos $(1997,2005)$ Five Hypotheses of SLA are very important in any CLTA framework. His Affective Filter Hypothesis, Input Hypothesis, Natural Order Hypothesis, Monitor Model, and his acquisition-learning dichotomies were reviewed in this study to guide the conduct of the descriptive-explorative investigation. The following flow chart shows the stages by which this study was conducted:

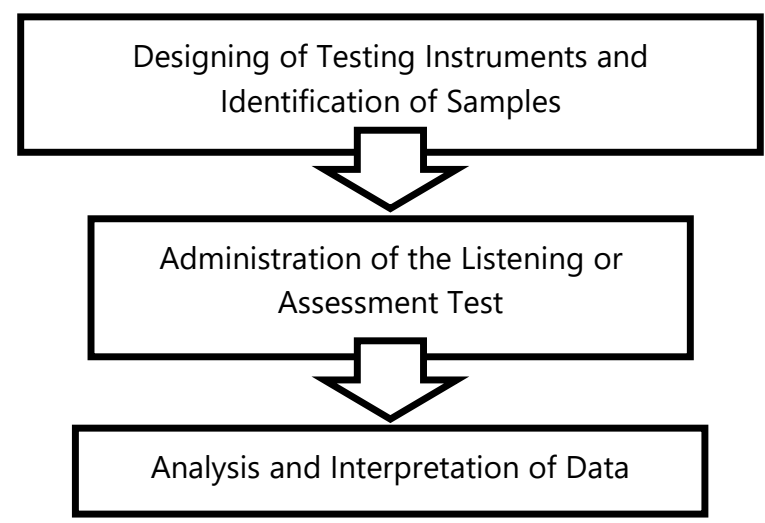

Figure 1. Schematic Diagram of the Flow Chart Illustrating the Stages of the Study

Initially, a modified communicative listening instrument was prepared based on Cohen's standardized testing instrument (1994) as cited in Murcia (2006). This assessment instrument was carefully critiqued and evaluated in terms of its reliability and validity with the help of language experts and practitioners. It consisted of two parts: inflectional patterns for singular and plural forms of subjects and predicates and inflectional patterns for present and past tense of verbs with 20 items for each part. Altogether, the listening test was composed of 40 multiple-choice items. These grammatical units were chosen for testing as they serve the basic linguistic structures in the grammatical competence of language learners in the universal context of ELT. Again, due to the coronavirus pandemic, the test had to be administered online. Controlling for any great differences in the subjects' physical environment, the online setting may be considered a great equalizer in the test's administration. The necessary testing protocol 
was discussed clearly to all the respondents, making sure they understood the test direction and that they were aware of the testing time.

To identify the subjects of the study from the research population, purposive sampling was employed. Criteria for selection of the study participants included average and low average I.Q. and English grades, the age range of 17-19, non-English speaking home backgrounds, middle-class socioeconomic status or SES, and without hearing problems enrolled in a Purposive Communication class in a state university in the province of Benguet, Philippines. Since the investigation was descriptiveexploratory in design, the study sample was, therefore, a heterogeneous group in terms of I.Q. and English abilities; twenty of the subjects were repeaters while twenty were regular students.

During the administration of the listening test through google meet, the respondents were instructed to listen attentively and determine whether the inflectional markers in each of the sentences would indicate singular or plural forms of subjects or predicates or present or past tense of the verb by shading the circle below the letter of their answer on the answer sheet through a google form. The listening test ran for about 30-35 minutes. The teacher-researcher gave clarity of delivery of the listening test utmost priority. The accent was neutralized so as not to intervene and affect the assessment result. The criteria of intelligibility, interpretability, and acceptability governed the testing protocol. All the test-takers or respondents were given prior orientation as to the objectives of the test and the study in general for research integrity and its required scholarly ethics. The items/aural texts were read twice. The following qualitative scale to determine the respondents' listening proficiency level was used.

\begin{tabular}{|l|l|l|}
\hline $\begin{array}{l}\text { Actual } \\
\text { Score } \\
\text { Range }\end{array}$ & $\begin{array}{l}\text { Qualitative } \\
\text { Description }\end{array}$ & Meaning \\
\hline $\begin{array}{l}16 \text { to } \\
20\end{array}$ & Very Good & $\begin{array}{l}\text { Able to recognize the inflectional markers in each of the } \\
\text { auditory texts and able to determine whether such markers } \\
\text { indicate singular or plural, present or past tense. }\end{array}$ \\
\hline 11 to & Good & $\begin{array}{l}\text { Able to recognize several inflectional markers but not able to } \\
\text { determine whether such markers indicate number (S/P) tense } \\
\text { (Present/Past) of the noun verbs. }\end{array}$ \\
\hline 6 to 10 & Fair & $\begin{array}{l}\text { Able to recognize several inflectional markers but not able to } \\
\text { determine whether such markers indicate number of tense of } \\
\text { the nouns or verbs. }\end{array}$ \\
\hline 0 to 5 & Poor & \begin{tabular}{l} 
None or few inflectional markers was recognized. \\
\hline
\end{tabular}
\end{tabular}

In order to validate the result of the listening test as to whether or not the respondents' knowledge of inflectional patterns is likewise evident in writing, descriptive composition writing was administered; however, since this investigation was limited only to the assessment of the respondents' skills in listening for grammatical distinctions, the written output of the study participants served only as secondary data used to extrapolate on their listening proficiency just like in any other descriptive-explorative research. Qualitative interpretation and conclusion were made from this secondary data.

To answer the specific questions of this study, the mean score was considered to determine the respondents' proficiency level. Frequency and sentence analysis were also employed to identify the common errors of the respondents.

\section{Results and Discussion}

Problem No. 1. What is the proficiency level of the college freshmen in listening for grammatical distinctions in terms of:

a. Inflectional patterns for singular and plural forms of the subjects or predicates?

b. Inflectional patterns for present and past tense of verbs?

The following table illustrates the proficiency level of the respondents in listening for grammatical distinctions in terms of inflectional patterns for singular and plural forms of subjects or predicates: 
Table 1. Listening Proficiency Level of the Respondents in terms of Inflectional Patterns for Singular and Plural Forms of Subjects or Predicates

\begin{tabular}{|l|l|l|l|}
\hline Range & Qualitative Description & Frequency & Percentage \\
\hline 16 to 20 & Very Good & 22 & 55 \\
\hline 11 to 15 & Good & 15 & 37.5 \\
\hline 6 to 10 & Fair & 3 & 7.5 \\
\hline 0 to 5 & Poor & 0 & 0 \\
\hline
\end{tabular}

Mean Score: 16.2 =Very Good

The above table reflects that 22 respondents (55 per cent) obtained scores between 16 to 20, with a qualitative description of "very good," 15 respondents (37.5 per cent) got 11-15, described qualitative as "good," 3 (7.5 per cent) obtained 6-10 or a qualitative "fair," and none ( 0 per cent) was "poor" according to the scale. The computed mean or score is 16.2 , qualitatively described as a "very good" which therefore means that, for the purposes of this study, the respondents were able to recognize the inflectional markers in each of the given sentences and were able to determine whether such markers indicated singular or plural forms of subjects and predicates.

This finding could be interpreted to mean that the respondents have proficient skills in listening for grammatical distinctions, especially in terms of inflectional patterns for singular and plural forms of subjects and predicates. This is in line with Bonet's (2003) and Schwartz's (2001) idea that a listening test can be internalized the expectancy grammar of the learner. But then again, it contradicts Harris's (2000) proposition that listening has been sadly neglected. Harris observes that while students develop a certain degree of reading and writing proficiency, their listening skills lag behind those two other skills. Renukadevi (2014) states that: "we gain $45 \%$ of language competence from listening, 30\% from speaking, 15\% from reading and 10\% from writing." The result of this investigation corroborates the positive views on listening proficiency as a scaffold to grammatical competence (Brown 1997, 2000; Canale and Swain 1985; Richards 1997, 2016).

Table 2 presents the respondents' proficiency level in listening for grammatical distinctions in terms of inflectional patterns for the present tense and past tense of verbs.

Table 2. Listening Proficiency Level of the Respondents in terms of Inflectional Patterns for Present and Past Tenses of Verbs

\begin{tabular}{|l|l|l|l|}
\hline Range & Qualitative Description & Frequency & Percentage \\
\hline 16 to 20 & Very Good & 12 & 30 \\
\hline 11 to 15 & Good & 25 & 62.5 \\
\hline 6 to 10 & Fair & 3 & 7.5 \\
\hline 1 to 5 & Poor & 0 & 0 \\
\hline
\end{tabular}

Mean Score: $15.02=$ Good

As shown in Table 2, the respondents' mean score is 15.02, qualitatively described as "good," which generally means that respondents could recognize some inflectional markers but not determine whether such markers exactly indicated the present tense or past tense of the verbs. More detailed scrutiny further shows that 12 (or 30 per cent) displayed "very good" proficiency level in the qualitative scale, as evidenced by their scores ranging from 16 to 20; 25 (62.5 per cent) of the respondents have "good" level of proficiency with scores from 11 to 15; 3 (7.5 per cent) obtained 6 to 10 score range with "fair" level of proficiency, and none (0 per cent) obtained a "poor" level of proficiency within the 1 to 5 score range.

Evidently, this study's respondents demonstrated an excellent proficiency level in listening for grammatical competence in inflectional patterns for present and past tense verbs. This result validates the study's hypothesis that listening proficiency impacts grammatical accuracy, henceforth an effective scaffold for grammatical competence. Likewise, the principles of CLTA as 
employed in the design and administration of listening tests or assessments can promote communicative competence in listening and translate to the simultaneous development of holistic language proficiency (Brown 1997,2000). The design of interactive listening tests that involve both bottom-up and top-down listening skills redound to the postering of overall micro and macro communication skills, recognizing that listening is a dynamic process involving many factors and skills.

Leki (2000) and Borja (2008) make a similar observation when they mention that the listening phase is an active process rather than mere passive activity. They describe the listening mechanism as an interactive process, and so they stressed that listening is "not a mere reception of auditory symbols." According to Leki (2000), Grammatical structures are even more exposed in wide listening sessions, especially when the goals are clear and understood.

This significant finding of the study serves to override the claim that of the five macro skills in communication, listening receives the least attention, unlike reading, speaking, writing, and viewing. The result actually points out that ESL learners may be aware of the importance and benefit of good listening skills for language learning. Since listening takes about 90 per cent of ESL learners' communication, the 40 freshmen may have developed metacognitive listening skills the monitoring competencies to assess and further their own listening proficiency as autonomous language learners. When a language skill becomes a habit for communication, it is easier to learn and maximize optimum learning (Brown 1997, 2000).

Problem No. 2. What are the common errors of the college freshmen in listening for grammatical distinctions in terms of:

a. Inflectional patterns for singular and plural forms of subjects and predicates?

b. Inflectional pattern for present and past tense of verbs.

Table 3 presents the frequency distribution of the common errors of the respondents in listening for grammatical distinctions in terms of inflectional patterns for singular and plural forms of the subjects and predicates.

Table 3. Common Errors of Respondents in Listening for Grammatical Distinctions in terms of Inflectional Patterns for Singular and Plural Forms of Subjects and Predicates

\begin{tabular}{|l|l|l|}
\hline ITEM NUMBER & KEY ANSWERS & NUMBER OF ERRORS (Frequency) \\
\hline 1 & A & 10 \\
\hline 2 & A & 7 \\
\hline 3 & B & 3 \\
\hline 4 & A & 2 \\
\hline 5 & A & 5 \\
\hline 6 & B & 0 \\
\hline 7 & B & 0 \\
\hline 8 & A & 3 \\
\hline 9 & B & 23 \\
\hline 10 & A & 8 \\
\hline 11 & B & 5 \\
\hline 12 & A & 21 \\
\hline 13 & A & 4 \\
\hline 14 & A & 5 \\
\hline 15 & A & 5 \\
\hline
\end{tabular}




\begin{tabular}{|l|l|l|}
\hline 16 & A & 16 \\
\hline 17 & B & 11 \\
\hline 18 & B & 6 \\
\hline 19 & A & 11 \\
\hline 20 & B & 9 \\
\hline
\end{tabular}

It can be gleaned from Table 3 that 23,21, and 16 out of 40 respondents got a wrong answer in items number 9, 12, and 16, respectively, in Part A, i.e., the test for inflectional patterns for singular and plural forms of subjects and predicates.

The findings revealed that the respondents were confused and/or distracted in some listening items when the sentence is embedded with intervening phrases or subordinating clauses. According to Flowerdew \& Miller (1996), as quoted in Renukadevi (2014), "difficulty in focusing and the physical environment" are two of the four problems in listening; these may have affected the respondents. The first two problems, "speed of delivery" and "new terminology and concept," may also have further affected the respondents due to the test's online nature. One other plausible explanation for the test result can be socio-psycholinguistic factors in language learning that look at culture and discourse structures as variables in the cognition and comprehension of grammatical structures or syntax and the overall sum of semantics. The word order of the first language or mother tongue also factors in when complex language tests in the second language are given. However, such issues can be hurdled through effective bilingual education, impacting listening pedagogy and instructional materials preparation. Further, the reading proficiency of ESL learners may also contribute to their listening proficiency in the target language. The finding of this study implies the need to expose the students to various types of discourses and reading materials to familiarize them with more challenging syntax or grammatical structures in terms of sentence dynamics and construction.

In item number 9, the sentence "the speakers imply that there is corruption" has a noun clause which caught the attention of the 23 out of 40 respondents and thought "is" was the main verb instead of the word "imply" and the word "speakers" as the subject. Similarly, in item number 12, the sentence "A tray of assorted fresh fruits" which might have caught the attention of the 21 respondents so that b (plural) became their answer instead of a (singular) because "a tray" is the subject and "makes" is the verb. These errors corroborate the views as aforementioned in the preceding discussion.

Conversely, all the respondents got the correct answer for items 6 and 7. In the sentence "our differences are all in the past," the subject "differences" clearly conveys that it is in the plural form because of the inflectional marker (-es) or the /-Is/ sound that is likely prominent, and that the verb "are" follows the subject immediately without the intervention of phrases or clauses between them. This result again validates the notion that simple syntax is not much an intervening variable in listening comprehension for grammatical accuracy among ESL learners familiar with the structure as sensitized in exposure and the scaffold of other language skills such as reading and writing (Brown 1997, 2000).

Table 4 presents the respondents' common errors in listening in terms of inflectional patterns for the present tense and past tense of verbs.

Table 4. Common Errors of Respondents in Listening for Grammatical Distinctions in terms of Inflectional Patterns for Present and Past Tenses of Verbs

\begin{tabular}{|l|l|l|}
\hline ITEM NUMBER & KEY ANSWERS & NUMBER OF ERRORS $(\mathrm{f})$ \\
\hline 1 & B & 13 \\
\hline 2 & B & 9 \\
\hline 3 & A & 22 \\
\hline 4 & A & 9 \\
\hline 5 & B & 9 \\
\hline 6 & A & 17 \\
\hline
\end{tabular}




\begin{tabular}{|l|l|l|}
\hline 7 & B & 1 \\
\hline 8 & A & 13 \\
\hline 9 & B & 0 \\
\hline 10 & B & 10 \\
\hline 11 & A & 31 \\
\hline 12 & A & 11 \\
\hline 13 & B & 0 \\
\hline 14 & A & 7 \\
\hline 15 & B & 9 \\
\hline 16 & A & 15 \\
\hline 17 & B & 5 \\
\hline 18 & B & 0 \\
\hline 19 & A & 0 \\
\hline 20 & A & 19 \\
\hline
\end{tabular}

As reflected in table 4, items 11, 3, and 20 have the highest number of respondents' errors. There are 31, 22, and 19 wrong answers, respectively. This second part of the test is on inflectional patterns for the present tense and past tense of verbs.

Interestingly enough, this part of the test has the highest instances of wrong answers. For example, in item number 11, 31 out of 40 respondents got the wrong answer. This means that more than 75 per cent of the respondents have difficulty focusing on the agreement between subject and predicate and the difficulty managing intervening phrases and clauses in the sentences they listened to, similar to what the respondents said during a class interview after the test. Again, this result points to linguistic differences of ESL learners' first language and second or target language as a plausible explanation but which can be overcome through effective error analysis by washback and backwash strategies aside of course from eclectic use of CLTA in the teaching of grammar and listening plus the rest of the language skills (Orillos 1997, 2005).

In the sentence "Our visitor, who comes from the city, is welcomed by the municipal official," the intervention of the objective clause "who comes from the city" or the word "welcomed" could have posed a difficulty for the respondents not to recognize the tense of the main verb. Another instance is presented in the sentence "The regulations forbid absences without permission to the president." The verb "forbid" was mistaken as being in the past tense since it ends with a/-d/sound vocabulary and overgeneralization can be encompassing problem here. Alternatively, the word surrounds the verb like "regulations" and "absences" can be the predicament that confused the respondents to recognize the tense of the verb.

On the other hand, none of the respondents gave incorrect answers to items 9, 13, 18, and 19. The sentence "Those days were called pretty" was very easy for the respondents because it is simple and it does not contain intervening phrases or clauses that may confuse the respondents. "Were" basically indicates plurality. Notice also that the verb and the adverb phrase in the sentence "My aunt cleaned my room early this morning." There is no doubt that the verb "cleaned" is in the past tense as it ends with an inflectional marker (-ed) or /-d/ sound. Besides, the adverb phrase "early this morning" compliments the fact that action was done earlier than the moment of utterance.

Meanwhile, there exists a somewhat alarming problem among the respondents' skills in observing correct inflectional patterns in composition writing. After tabulating the listening test result, a composition writing test was administered to validate the results and find out the respondents' performance level in grammar. The dichotomy between competence and performance strongly impacts this study because both hold some language proficiency assessment criteria. Gleason (1989) asserts that "what learners actually know about language (competence) can be measured through how they say and understand (performance) within the context of social conversation.' 
The succeeding sentences were copied (verbatim) from the writing outputs of the respondents:

"that may image are symbolized in the middle of the story the word BIG

FISH, and with their top are the branches of the tree, the word BIG

FISH are represent to the people ... that BIG FISH is the body of the branches."

"it shows us that there are many struggles in our life ... It also

show us that there are many problems we need to face ..."

"But in the picture the man surpassed the trees which means he had overcome all the hardships ... this represent his goal in life ... the

Clouds represent another trials...."

"Based on what we are see, that story entitled Big Fish is the hardest to appreciate and analyzed because of the event or chapter are full of symbols ..."

The above texts may suggest that the respondents know the basic rules of inflectional patterns but are not particularly cautious in using them. These instances of errors or mistakes can be attributed to performance problems such as lack of practice in using the English language or attention rather than ignorance of the basic rules of English grammar. It is also possible that the study participants may be monitor by users, where they may know the correct forms to use but careless and lazy to double-check their outputs in the target language (Krashen, 1985).

\section{Conclusion}

The respondents have very good proficiency level in listening for grammatical distinctions in terms of inflectional patterns for singular and plural forms of subjects or predicates and a good proficiency level in terms of inflectional patterns for present and past tense of verbs. However, some problems exist among the respondents' listening skills for grammatical distinctions, as evidenced by the frequency distribution of errors noted in table 3 and 4, revealing the first three items with the most frequent incorrect answer.

In light of the findings and conclusions, it is recommended that ESL teachers should strive to integrate interactive listening in the teaching of communicative grammar in the classroom. Moreover, the teaching of listening as a skill for learning must be given utmost attention since it can enhance learners' sensitivity to language structure, impacting holistic language proficiency as communicative skills scaffold and overlap in the learning continuum. Students must be exposed to varieties of sentence structures, lengths, and discourse types. At the same time, it is recommended that they must be meticulous and discerning in handling word/s like modifiers or intensifiers that surround the subject and the verb in the sentence. Intervening words or clauses may be considered distracting as the students process the simple structure first before they can process other words. In the same turn, modifiers that clarify the verb tense aid in the students giving the correct answers. These are the context clues that ESL teachers should point out to their students during listening exercise. Critical to developing the grammatical competencies of the students would be communicative exercises in Transformational Grammar or TG as forwarded by Chomsky (as cited in Celce-Murcia 2003). Students should be taught TGs four principles of addition, subtraction, substitution, and permutation in sentence construction where embedding and modifiers are likewise learned.

Writing activities must also be used to reinforce the development of ESL learners' listening skills and grammatical skills. CLTA advocates highlight the importance of writing in the mastery of grammatical units as it is the highest and most challenging form of discourse, but that is not to downplay the other four language skills. When ESL learners are given ample and reasonable opportunities to write for different purposes, they develop an array of micro and macro communication skills tapping on their grammatical knowledge or competence. As asserted in this study, the argument about the dichotomy between competence and performance has been used more as complementary abilities rather than counterproductive to language learning. Therefore, this study recommends that ESL teachers evaluate their pedagogy and align this with eclectic CLTA practice not just for teaching but also for testing as in the assessment of listening proficiency. On the other hand, ESL learners should be taught explicit and direct strategy instruction in the five macro skills, particularly in listening, as daily communication in the orality of their society is comprised by 90 per cent of listening aside from the demands of virtual online language learning in the new landscape. Practical and authentic listening activities may include dialogues and conversation exercises, problem-solving, role plays and simulations, character analysis, asking and giving directions, and community language learning that may be all done online. Thus, an overall rounded holistic approach, using all five fundamental language skills, produces well-rounded students with practical communicative competencies. 
This study further recommends that ESL teachers regularly monitor and assess the students' proficiency level not only in listening or grammar but also in the four other language skills. Such a periodic assessment would reveal the aspects where much more attention in ESL teaching and learning is needed that can inform and lead to curriculum renewal for a more relevant and responsive English language education.

For a more comprehensive study on the listening proficiency of ESL students enrolled in the study site of this investigation, a triangulation of methodology is recommended. Administering a listening comprehension test for the same group may be considered to validate this completed study's results best.

Funding: This research received no external funding.

Conflicts of Interest: "The authors declare no conflict of interest.

\section{References}

[1] Al-Batal, M. (2010). Challenges in Teaching Listening. https://coerll.utexas.edu/methods/modules/listening/01/challenges.php

[2] Bonet, D. (2003). The business of listening. Thompson Place.

[3] Brown, H. D. (2000). Principles of language learning and teaching (Vol. 4). New York: Longman.

[4] Celce-Murcia, M. (2006). Teaching English as a second language. Heinle \& Heinle Thompson Learning.

[5] Corpuz, B., Salandanan G., \& Rigor D. (2006). Principles of teaching II. Lorimar Publishing Inc.

[6] Dictionary.com. (2020). Listen. https://www.dictionary.com/browse/listening?s=t

[7] Gleason, J. B. (1989). The development of language. Merill Publishing Company, A Bell and Howell Information Company.

[8] Harris, D. P. (2000). Testing English as a second language. McGraw-Hill.

[9] Lado, R. (2000). Lado English Series. Prentice-Hall.

[10] Leki, A. (2000). Teaching second language: Where we seem to be. English Teaching Forum.

[11] Miller, R. (1998). Greater expectation to improve students' learning. Greater Expectation National Panel

[12] Orillos, L. (2008). Second Language Acquisition Theories and Principles. Quezon city: UP Open University.

[13] Renukadevi, D. (2014). The Role of Listening in Language Acquisition: The Challenges \& Strategies in Teaching Listening. http://www.ripublication.com/ijeisv1n1/ijeisv4n1_13.pdf

[14] Richards, J. (2016). Lecture Series. UST Graduate School. Espana, Manila.

[15] Schwartz, A. (2001). Listening in a foreign language. In Grace Stovall Burkart (Ed.), Center of Applied Linguistics.

[16] Shwartz, M. A. (2009). Teaching English. http//www.nclrc.org/essentials/listening/developlisten.htm

[17] Vilamin, A. (1998). Innovative strategies in teaching communication arts. Phoenix Publishing House.

[18] Zhou, J. (2003). New wine in an old bottle: Innovative EFL classrooms in China. LATEFL VOL NO. ISSUE NO. April-May 2003 